\title{
Incidental vocabulary learning in classroom communication tasks
}

Language Teaching Research 17(2) 164-187

(C) The Author(s) 2013 Reprints and permissions: sagepub.co.uk/journalsPermissions.nav DOI: 10.1 I77/I362I688I24608|4

Itr.sagepub.com

\section{Jonathan Newton}

Victoria University of Wellington, New Zealand

\begin{abstract}
This study investigated the ways in which two groups of four adult learners of English as a second language (ESL) responded to unfamiliar words they encountered in four communication tasks and the effect that different levels of engagement with these words (including negotiation of form and meaning) had on subsequent recall of word meaning. Of the four tasks, two were information gap tasks and two were opinion gap tasks. The results showed a strong task type effect on both the amount and type of negotiation, with more negotiation of the form of words (including spelling and pronunciation) in the information gap tasks and, conversely, more negotiation of meaning in the opinion gap tasks. Through the negotiation process, the learners in the study provided accurate information to each other on word meaning. However, only a small proportion of the total number of unfamiliar words in the tasks were actually negotiated for meaning. The prediction that negotiated words would be more likely to be learnt was confirmed, although the learners also showed improved recall of many words that had not been negotiated. Averaged across learners and tasks, the post-test gains approximated to four instances of word learning per 30 minutes of task work, a gain measured three days after the words were met in the tasks. Seen as a proportion of unfamiliar words in the pre-test these are gains of around one in every three unfamiliar words met in the tasks. The finding that much of the improved recall of word meaning was for words that had not been negotiated indicates that the role of negotiation in learning through communication tasks needs to be viewed from a wider perspective.
\end{abstract}

\section{Keywords}

Incidental vocabulary learning, negotiation, task-based interaction

\section{Introduction}

While there is a large body of research on language learning through tasks, on the one hand, and through incidental vocabulary learning, on the other, research into incidental

\section{Corresponding author:}

Jonathan Newton, School of Linguistics and Applied Language Studies, Victoria University of Wellington, PO Box 600, Wellington 6I40, New Zealand.

Email: jonathan.newton@vuw.ac.nz 
vocabulary learning through communication tasks has been relatively sparse (though for important studies in this area see Ellis, 1995; Ellis \& He, 1999; De La Fuente, 2002; Kim, 2008). It is likely, however, that learners will often meet unfamiliar words in the texts and materials for communication tasks as well as in the spoken input from other learners during group work and, furthermore, that they will need to engage deeply with these words in order to complete the task successfully and in ways that are congruent with Laufer and Hulstijn's Involvement Load Hypothesis (Laufer and Hulstijn, 2001). This makes the communication task a potentially valuable source of opportunities for incidental vocabulary learning, and one that warrants further investigation. Hence, this study examined the ways in which learners responded to and engaged with unfamiliar words that they met in a series of communication tasks and the impact of these encounters on learning the meaning of these words as measured by gains in a test of receptive recall of word meaning.

\section{Literature review}

The process by which language learners negotiate their way through communication problems in communication tasks has been argued to facilitate language acquisition in a number of ways. Through negotiation of meaning, learners notice and attend to learnable language features in the input. Here also, learners can use the 'scaffolding' of contingent turns to syntacticize meanings in increasingly complex ways (Pica, 1994). And here learners have opportunities to test out hypotheses about the language and to receive feedback on the quality of their production (Swain, 1995). Such are some of the main roles attributed to interaction and negotiation of meaning in second language acquisition. (For extensive treatments of these claims, see Doughty, 2000; Gass, 1997; Gass, Mackey, \& Pica, 1998; Long, 1996; Mackey, 2007.)

These ideas led to the claim that task types that generate more negotiation are more useful for language learning. Early studies showed information gap activities to do just this (Doughty \& Pica, 1986; Long, 1980). The detailed exchange of information and convergent (closed) outcome typical of such tasks usually requires a high level of mutual comprehension and comprehensibility, which can only be achieved by learners negotiating understandings back and forth (Ellis, 1991; Pica, Kanagy, \& Falodun, 1993). However, the superiority of these tasks has been challenged in a number of studies, including Foster (1998), Nakahama, Tyler, and Van Lier (2001) and, in the context of computer mediated communication, Smith (2003). Foster (1998) found that the effect of task type on negotiation shown in laboratory studies failed to extend to the intermediate level EFL (English as a foreign language) classroom setting in which her study was situated. More importantly perhaps, she found that the learners in her study negotiated for meaning very infrequently (similar results were reported by Foster \& Ohta, 2005), and then, almost invariably, over vocabulary items. Two other classroom-based studies found greater levels of negotiation between learners than Foster, but in lower amounts than in the laboratory (Slimani-Rolls, 2005) and with little task effect (Eckerth, 2009).

In a study designed to directly test Foster's (1998) claims, Gass, Mackey, and Ross Feldman (2005) compared tasks performed in laboratory and classroom settings. In contrast to Foster, they found that information exchange tasks generated significantly 
more negotiation of meaning than opinion gap tasks, with task type having a greater effect on the amount of negotiation than the setting in which the research was carried out (classroom or laboratory). In the context of native-speaker-non-native speaker (NSNNS) interaction, Nakahama et al. (2001) also investigated negotiating behaviour in information gap activities, in this case compared with unstructured conversations. While they also found more negotiation in the information gap tasks, their close analysis of other syntactic and pragmatic features of the interactions showed that the conversations offered a richer range of learning opportunities. Foster and Ohta (2005) also looked beyond negotiation and towards other social interactive processes such as repair and peer assistance that were frequent in their learner-learner interaction data and that appeared to play important roles in fostering language development.

Overall, results from studies addressing the question of 'how much' negotiation is produced under different task type conditions are rather mixed. This is perhaps unsurprising given the range of design features of these studies and the varied settings in which they have been conducted. But there is a deeper problem here. In its barest terms, the implication of this research that 'more is better', fails to account for the way different task types may influence the quality of negotiation, including, what is negotiated, how, and with what success. Early research on negotiation tended to ignore qualitative aspects of negotiation (see, for example, Doughty \& Pica, 1986), although, subsequently, research has placed greater emphasis on this (Lyster, 1998; Lyster \& Ranta, 1997; Nakahama et al., 2001; Pica, Lincoln- Porter, Paninos, \& Linnell, 1996; Smith, 2005; Van den Branden, 1997). The present study maintains this emphasis by looking at one dimension of negotiation in depth, namely the ways in which learners negotiate the meaning of unfamiliar words they encounter in communication tasks, and how successful this process is for vocabulary learning.

Many studies have reported that negotiation of meaning mostly involved early vocabulary and only infrequently any other aspect of language. An important source of evidence for a link between negotiation and vocabulary learning comes from a series of studies by Ellis and associates. Ellis, Tanaka, and Yamazaki (1994) report on two related studies in which Japanese high school students of English performed one way tasks which required them to follow instructions for placing pictures of kitchen objects (for which they did not know the English words) in specific places in a picture of a kitchen. The task was performed under three different conditions: baseline (teacher-read scripted directions based on NS-NS performance of the task), premodified (based on NS-NNS performance), and interactionally modified (baseline directions but with opportunities for interaction). The group receiving interactionally modified input showed superior comprehension of the input and outperformed the other two groups on a series of posttests on the meaning of words from the tasks. However, in a re-analysis of this data Ellis (1995) found that the premodified input condition outperformed the interactionally modified input condition when time on task was taken into account.

In a third study using a similar design and the same tasks, Ellis and He (1999) addressed the lack of opportunities for learner output in the previous studies. A 'negotiated output' condition was added in which learners worked together in pairs to negotiate their understandings. Students in this condition outperformed those in the other two conditions on all of the five post-tests of vocabulary knowledge. De La Fuente (2002) obtained similar 
findings in a study of Spanish language learners performing listening comprehension tasks with native speakers. She found that only negotiation with pushed output promoted both receptive and productive vocabulary learning. These studies provide strong support for the claim that when learners can negotiate to clarify the meaning of new words during a task, incidental vocabulary learning is more likely to occur than in tasks in which opportunities for negotiation are not available.

These studies all involve interaction with a teacher or native speaker. However, communication tasks are typically carried out by learners in pairs and groups, and so it is important to also establish from evidence the vocabulary learning opportunities available through learner-learner interaction. Studies that have investigated this issue have generally confirmed the positive findings from the studies involving teachers or native speakers. Adams (2007) used tailor made post-tests to measure learning of targeted forms (both grammatical forms and vocabulary) that pairs of adult ESL learners negotiated with one another as they worked on a series of communication activities. She found moderate to high rates of learning for all four forms tested, although she cautions that some of this learning was not in the direction of the target form. Hall (1991) investigated the learning of mathematical vocabulary through communicative pairwork by 11 - to 13-year-old students. He found that students doing split information activities made significantly greater vocabulary learning gains than students working within a teacherfronted arrangement with a reading focus. Hall concluded that split information activities provide opportunities for talk that increase both language knowledge and content knowledge. He also argued that the generative use of the targeted word by the learners in this study was a key factor leading to acquisition, a finding confirmed by Joe (1998) in the context of read and retell activities.

The findings from these studies lend some support to the claim that learning is most effective when learners focus on language form in response to a communicative need rather than in anticipation of it (Long \& Robinson, 1998). Laufer and Hulstijn (2001) carried out a study relevant to this claim. They investigated the hypothesis that incidental vocabulary learning was determined by the extent to which learners attended to vocabulary encountered incidentally during meaningful language use. They operationalized 'involvement' as a combination of three factors: need (i.e. the need to understand the word for comprehension); search (trying to figure out the word); and evaluation (comparing a word with other words and using it in communication). In the study, learners encountered unfamiliar words in texts in which levels of involvement were carefully controlled. They found that higher involvement with unfamiliar words led to significantly better retention. As Hulstijn (2001) concluded in a survey of research into incidental and intentional vocabulary learning:

It is the nature of information processing which determines retention. The more a learner pays attention to a word's morphological, orthographic, prosodic, semantic and pragmatic features and to intra-word and inter-word relations, the more likely it is that the new lexical information will be retained. (p. 15)

A study by Kim (2008) involved partial replication of Laufer and Hulstijn (2001). In this study, adult ESL learners performed various reading and composition tasks seeded with 
unfamiliar vocabulary in which the involvement load had been kept constant. Kim found that vocabulary learning and retention by learners was similar across tasks in which the involvement load was kept constant. Moreover, the benefits of increased learner involvement were not influenced by learners' proficiency levels. Although the Involvement Load Hypothesis is not directly tested in the current study, it offers a way of viewing negotiation qualitatively. Through negotiation, learners interactively acknowledge a need, search for meaning, and evaluate the information they receive by putting it to immediate use. Underpinning the current study is a hypothesis with parallels to the Involvement Load Hypothesis, namely, that the quality of negotiation of unfamiliar words met incidentally in a task performance will determine whether and how well these words are learnt.

As this brief review has shown, studies of vocabulary learning from interaction focus almost exclusively on learning occurring through negotiation or language related episodes. It is of course easier to match such overt signals with subsequent learning. However, learning can also occur simply through meeting a word in context (Nagy, Herman, \& Anderson, 1985), and the present study also looks at this.

\section{Methodology}

\section{Aim and research questions}

This study investigated the ways in which adult ESL learners responded to and engaged with unfamiliar words that they met in two types of communication tasks, and whether these encounters resulted in learning. In particular, the study looks at the effect of task type (opinion gap vs. information gap) on the quantity and quality of negotiation, and at the question of whether negotiated words were more likely to be learnt than words that were not negotiated for meaning. Learning was measured using pre-/post-tests of recall of word meaning.

The study addresses five research questions. The first three focus on patterns of engagement with unfamiliar words and the final two on the relationship between negotiation and learning.

1. How did the learners respond to unfamiliar words?

2. How accurate was learner-learner negotiation of unfamiliar words?

3. Did the type of task the learners performed affect their willingness to negotiate unfamiliar words?

4. Did the learners learn the meaning of unfamiliar words they met in communication tasks?

5. Were negotiated words more likely to be learned than non-negotiated words?

\section{Participants}

Participants in the study were enrolled in a 12 week, pre-entry, intensive academic English language programme at a New Zealand university. The programme was largely content based and task based and provided 25 hours of classroom instruction per week. 
The participants were from an intact class of 23 students who had volunteered to participate in the study. The class had been together for two and a half months at the time the study was carried out. The proficiency level of the class was estimated to be between 4.5 and 5.5 on the nine-point IELTS scale. This estimate was based on their performance on an in-house placement test (a vocabulary test, a cloze test and a dictation) that has been extensively calibrated against the IELTS bands. Broadly speaking a 4.5-5.5 band range equates to low-intermediate proficiency. Although the whole class participated in the study, data from only eight students (two groups of four) is reported on in this article. All eight participants had been in the country for less than six months.

To place students in the class in groups for the purposes of the study, a stratified sampling procedure was used. First, the class was stratified according to first language (L1) background and gender, and then students were placed sequentially but randomly from the L1 and gender categories into five groups (four groups of four and one group of three $=23$ ). Data from the two most closely matched of these five groups are reported in this article. The two groups each contained two male and two female students with different L1s (Cantonese, Farsi, Indonesian, Mandarin, and Japanese). The learners were between 22 and 33 years of age. The close matching of the two groups was considered important because of the repeated measures, counterbalanced design of the study. It should be noted that in the course of regular classroom work, the composition of groups in the class was often determined by the teacher to ensure maximum diversity within groups. The grouping arrangements made for this study were therefore not particularly intrusive or novel to the students.

\section{Tasks}

Four tasks were used in the study: two information gap tasks and two opinion gap tasks. Each information gap task shared a topic with a matching opinion gap task. Tasks 1 and 3 involved criteria for selecting patients for surgery and Tasks 2 and 4 the layout of a zoo. Control of topic across task types is rarely attempted in studies in this field. The four tasks are described in Table 1.

The task type classification developed by Pica et al. (1993) was used to classify the four tasks in the study, as shown in Table 2. The two information gap tasks involved

Table I. The four tasks used in the study.

\begin{tabular}{llll}
\hline Task & Task type & Topic & Detail \\
\hline I & Information gap & Surgery & $\begin{array}{l}\text { Exchange information to complete: (a) an information grid } \\
\text { profiling six people waiting for surgery; and (b) a list of eight } \\
\text { non-medical criteria for identifying eligible patients. Use } \\
\text { these criteria to rank the six people. }\end{array}$ \\
2 & Opinion gap & Surgery & $\begin{array}{l}\text { Exchange information to complete a zoo plan. } \\
\text { Reach consensus on the order of priority for surgery of a } \\
\text { list of people requiring heart surgery. } \\
\text { Reach consensus on the most suitable layout of a zoo (from } \\
\text { Ur, I98I, pp. 80-83). }\end{array}$ \\
\hline
\end{tabular}


Table 2. Features of the four tasks in the study.

\begin{tabular}{llllc}
\hline & $\begin{array}{l}\text { Information } \\
\text { flow }\end{array}$ & $\begin{array}{l}\text { Interaction } \\
\text { requirement }\end{array}$ & Goal orientation & $\begin{array}{c}\text { Outcome } \\
\text { options }\end{array}$ \\
\hline $\begin{array}{l}\text { Information gap } \\
\text { (Tasks I and 2) }\end{array}$ & two-way & +required & + convergent & closed \\
$\begin{array}{l}\text { Opinion gap } \\
\text { (Tasks 3 and 4) }\end{array}$ & two-way & - required & + convergent & open \\
\hline
\end{tabular}

two-way required information exchange, a convergent goal orientation and a single closed outcome. In procedural terms, each group member held a unique portion of the task input and was required to verbally describe this portion so that others could reconstruct the full version of the input. Each learner's contribution was essential to the successful completion of the task.

The two opinion gap tasks involved two-way optional information flow, a convergent goal orientation and multiple open outcome options. In procedural terms, interlocutors shared access to the task input and used this to reach consensus on a task outcome of which a number of options were feasible. While all group members were expected to participate (two-way information flow), neither participation nor comprehension were essential; it was conceivable that the tasks could be completed even if some group members opted out or feigned comprehension.

\section{Design}

The two groups of four learners performed the same four tasks in a pre-test, post-test repeated measures design (see Table 3 ). The order of treatments was counterbalanced to control for practice effects and for possible order effects of task type and topic. For Group 1, the information gap zoo task preceded the opinion gap zoo task, while the opinion gap surgery task preceded the information gap surgery task. Group 2 performed the two sets of tasks in reverse order. The students performed familiarization tasks on day 1 of the study to ensure that both task types were equally familiar prior to the treatments. Each task performance took place on a separate day with a two-day break separating performances one and two from performances three and four.

Communication tasks were a regular part of the programme for the participants in the study, and care was taken to fit data collection into their class program with minimal intrusion. An intact class was used and teaching staff acted as research assistants. Although data from only two groups of students were used in the study, the whole class carried out all the tasks, and recording equipment was used with all other groups in order to avoid highlighting the two target groups.

On day one of the study the class sat a vocabulary pre-test and performed two short tasks to ensure familiarity with the task-types and procedures. In each of the subsequent sessions the class broke into groups and moved to assigned rooms adjacent to the classroom to do the tasks. The tasks were introduced by research assistants using written instructions. They were all junior teaching staff and so were known to the students. The students were encouraged to try and work out the meaning of any unfamiliar words they 
Table 3. Design of the study.

\begin{tabular}{|c|c|c|}
\hline Day & Group I $(n=4)$ & Group $2(n=4)$ \\
\hline I & \multicolumn{2}{|c|}{ Familiarization tasks; vocabulary pre-test } \\
\hline \multicolumn{3}{|c|}{ Task performances: } \\
\hline 2 & Information gap: Zoo & Information gap: Surgery \\
\hline 3 & Opinion gap: Surgery & Opinion gap: Zoo \\
\hline 4 and 5 & Break & Break \\
\hline 6 & Opinion gap: Zoo & Opinion gap: Surgery \\
\hline 7 & Information gap: Surgery & Information gap: Zoo \\
\hline 10 & \multicolumn{2}{|c|}{ Vocabulary post-test } \\
\hline
\end{tabular}

met in the tasks among themselves rather than consult an assistant or dictionaries (which were not available during the task performance in any case). While this instruction might appear to have primed the students to negotiate word meanings, it is unlikely to have had this effect. Communication tasks were typically introduced in this way in the wider programme as part of the ethos of using the tasks for meaning-focused language use. If a group needed further assistance with an unfamiliar word, the assistants were instructed to intervene and offer help. If this was done it was noted and taken account of in the data analysis (see Table 8 below).

\section{Data collection}

About four hours of video and audio recordings of target task performances were made and transcribed. Video footage was used to identify speakers who were difficult to distinguish from one another in the audio recordings. To minimize the potential inhibiting effect of recording equipment, the cameras and audio recorders were used in the classroom on several days prior to the data collection sessions.

\section{Task vocabulary}

The task sheets for the four tasks contained 109 content words (excluding function words) (see Table 4). Because the tasks were not designed primarily for the purpose of researching vocabulary learning, the number of content words and the nature of these words was not tightly controlled across the tasks, and so the learners encountered around $20 \%$ more words in the opinion gap tasks than in the information gap tasks (62 words vs. 47 words). However, the use of parallel topics across task types offered some control of differences between the vocabulary encountered in each task type. The Vocabulary Profile Programme (Nation \& Heatley, 1996) was used to analyse the word frequency levels of the vocabulary from the tasks. It showed similar proportions of high and low frequency words in the input texts for the two task types. Thus, $43 \%$ of the words in the opinion gap tasks and $40 \%$ in the information gap tasks were high frequency (that is, they appeared in the word lists for the 3000 most frequent words in English). The remaining $57 \%$ and $60 \%$ respectively for the two task types can be considered low frequency words since they did not appear on these lists. 
Table 4. Vocabulary from the four tasks selected for pre- and post-testing.

\begin{tabular}{|c|c|c|c|}
\hline \multicolumn{2}{|l|}{ Opinion gap } & \multicolumn{2}{|l|}{ Information gap } \\
\hline Task I: Surgery & Task 2: Zoo & Task 3: Surgery & Task 4: Zoo \\
\hline alive & alarmed & assume & antelope \\
\hline atheist & cafeteria & badminton & aquarium \\
\hline available & camels & benefit & buffalo \\
\hline cancer & crocodiles & characteristics & café \\
\hline catholic & deer & chess & dump \\
\hline chemistry & disturbing & conversation & elephant \\
\hline Christian & dolphins & cricket & first-aid \\
\hline criminal & empty & team & fountain \\
\hline critically & enclosure & electrician & gorillas \\
\hline custody & foxes & fluent & lion \\
\hline data & giraffes & fulfils & map \\
\hline divorced & harmless & hockey & palm-tree \\
\hline drinker & hippos & moderate & parrot \\
\hline ex-husband & hyenas & occupation & pond \\
\hline ex-mayor & job & per-annum & reptile \\
\hline examine & layout & preferable & shelter \\
\hline excessive & llamas & qualification & swing \\
\hline female & overcome & rock-climbing & symbols \\
\hline fraud & pandas & rugby & tractor \\
\hline heart & pelicans & salary & walnut-tree \\
\hline Hindu & pool & soccer & zoo \\
\hline hospital & predator & specialist & \\
\hline lecturer & smelly & status & \\
\hline medical & task & team & \\
\hline Muslim & & tradesman & \\
\hline operation & & volleyball & \\
\hline \multicolumn{4}{|l|}{ over-weight } \\
\hline \multicolumn{4}{|l|}{ parliament } \\
\hline \multicolumn{4}{|l|}{ patient } \\
\hline \multicolumn{4}{|l|}{ Ph.D. } \\
\hline \multicolumn{4}{|l|}{ suitability } \\
\hline \multicolumn{4}{|l|}{ surgeon } \\
\hline \multicolumn{4}{|l|}{ surgery } \\
\hline \multicolumn{4}{|l|}{ survive } \\
\hline \multicolumn{4}{|l|}{ task } \\
\hline \multicolumn{4}{|l|}{ technique } \\
\hline \multicolumn{4}{|l|}{ transplant } \\
\hline \multicolumn{4}{|l|}{ widow } \\
\hline 38 & 24 & 26 & 21 \\
\hline 62 & & 47 & \\
\hline
\end{tabular}




\section{Pre- and post-testing of task vocabulary}

A simple test of receptive recall of task vocabulary (Nation, 2001, pp. 30-31) was constructed for use as a pre- and post-test. The test contained the 109 words listed in Table 4 listed on the test paper in random order with a space beside each item for a written response. The spoken form of the words was also provided by the supervisor who read the list of words aloud at the beginning of the test. The learners were instructed to identify any words they recognized and provide a translation or definition of the word either in their L1 or in English. The tests were completed independently and silently by each participant except when a request was made for the supervisor to read a word aloud again. All the learners completed the test within 30 minutes. The tests were taken from each student immediately they were completed. All the learners used their L1 extensively in the test, and the papers were marked by bilingual speakers of each of the languages used. The bilingual markers were asked to back-translate into English any L1 responses that they felt were ambiguous.

The pre-test was set one day prior to the first task performance and the post-test three days following the last task performance (see Table 3 above). While a combination of immediate and delayed post-tests is usually desirable, the schedule for the programme in which the learners were involved precluded opportunities for delayed tests beyond the end of the second week of the study.

The results of the vocabulary pre-test provide information about how much of the task worksheet vocabulary was known by all, some, or none of the learners in a group. Variable knowledge of task vocabulary by different learners in a group is an important pre-condition for collaborative work on unfamiliar vocabulary through which learners can use one another as a resource for information on unfamiliar words. Table 5 summarized the results of the pre-test. Of the 109 words tested, a minority -31 for Group 1 and 32 for Group 2 - were known by all the learners in the group. Of the remaining words, $62 / 60$ were known by at least one of the four members of each group but not known by at least one other group member. This is a substantial number of words for which learners in the groups have the requisite knowledge to help each other. The remaining 16/17 words were not recognized in the pre-test by any members of the respective groups.

Variability in the word knowledge of individual learners at a similar proficiency level also has been shown by Saragi, Nation and Meister (1978). Using a word knowledge test with Indonesian learners of English as a foreign language, the authors found that only $12 \%$ of the words were known by every learner, while $30 \%$ of the words were known by at least one learner (20 learners were tested). These learners were in a situation in which exposure to English was mostly limited to a set curriculum, classroom and textbook.

Table 5. Prior knowledge of task vocabulary.

\begin{tabular}{lcc}
\hline Pre-test results & Group I & Group 2 \\
\hline I. Words known by all group members & 31 & 32 \\
2. Words known by some but not all group members & 62 & 60 \\
3. Words not known by any group members & 16 & 17 \\
Total number of words tested & 109 & 109 \\
\hline
\end{tabular}


Variability in word knowledge between students is likely to be even greater in an ESL context such as in the present study where learners come from varied backgrounds and where exposure to the target language in the social environment is rich and varied.

\section{Results}

\section{How did the learners respond to unfamiliar words?}

As seen in Table 5, across both groups, 155 words (rows 2 and 3 tallied) were not known by at least one member of a group. The first question then is how did the groups respond to these unfamiliar words as they attempted to perform the task? To answer this question, four levels of engagement with unfamiliar words in the task performances were identified. The learners either: (1) avoided the word; (2) used the word but without any negotiation; (3) negotiated the form of the word; or (4) negotiated the meaning of the word. These four levels of engagement are expanded on below.

a Level I:Avoided using the word. This response involved simply not using words that appeared in the written input to the task. For example the word atheist which appeared in the input sheet for Task 1 and was not known by three members of group 1 was also not used at all by this group in their performance of this task.

b Level 2: Used the word but without negotiation of form or meaning. This response involved at least one member of the group using the word in the task performance but without any attempt by learners who had not recognized the word in the pre-test to seek clarification of the form or meaning of the word. For example, the word medical in the phrase medical suitability (from Task 1), which was not recognized in the pre-test by a member of group 2 , was used in the task performance but was not negotiated for form or meaning.

c Level 3: Negotiated the form of the word. This response involved using an unfamiliar word and negotiating its form (i.e. its spelling or spoken form) but not attending explicitly to the meaning of the word. For example, the word pond (from Task 4) was not recognized by three members of Group 1 in the pre-test. As seen in excerpt 1, when the word was encountered in the task, the group took 12 turns to clarify the spelling of the word and then proceeded with the task without any attention to what the word means.

\section{Excerpt 1:}

S3 we call it a pond, p. o. n. d.

S1 oh yeah

S3 'a' article ah

S2 p. o.?

S3 p.o.n. d.

S1 pond

S3 pond yeah

S4 pond

S2 p. o. n. e. d.?

S1 p.o.n.d.

S3 p. o. n. d. yeah n. d., p. o. n. d.

S2 o. oh yeah ah pond 
$d$ Level 4: Negotiated the meaning of the word (+/- negotiation of form). This response involved negotiating explicitly the meaning of a word, usually in response to a clarification question by someone in the group. For example, the word fluent appeared in the input sheet for Task 3 in the phrase must be fluent in at least two languages which have different written forms and was negotiated in the following way:

\section{Excerpt 2:}

S3 and be fluent in two languages?

S1 pardon?

S2 huh?

S3 be fluent in two languages which have different written forms

S3 can can speak two languages

This excerpt shows S3 responding to clarification requests from S1 and S2 by paraphrasing the meaning of the phrase fluent in two languages as can speak two languages ... Further examples of how the learners negotiated word meaning are provided in Table 6 . In cases in which meaning negotiation also included negotiation of form, the form and meaning negotiation moves were categorized accordingly. However, the overall treatment of the targeted word was classified on the basis of the deepest level of engagement achieved, namely, Level 4 (negotiation of meaning).

Table 6. Negotiation of meaning: a sample of responses to requests for clarification of word meaning.

\begin{tabular}{|c|c|}
\hline Target word & Response \\
\hline filled & should put something inside \\
\hline harmless & weak animals \\
\hline zebra & black and white coloured horse \\
\hline hippos & big animal live in the pool, like elephant, big mouth, brown. \\
\hline predators & $\begin{array}{l}\text { one animal eat another animal ... like lion ... crocodile ... to attack, because } \\
\text { its often will attack }\end{array}$ \\
\hline disturbing & if you're studying and I'm making a lot of ... noise ... \\
\hline Hindu & it's a religion \\
\hline
\end{tabular}

Table 7 displays results on the level of engagement with content words in the written input for the tasks. Columns 1 and 3 show the number of words from the 109 tested words at each level of engagement. This data is for all words, known and unknown from the written input. Columns 2 and 4 provide a subset of this data, reporting the level of engagement with learnable words, that is with words in the pre-test that at least one group member did not recognize. This is the most useful data since it eliminates known words from the analysis. In all, 155 words (the combined totals for columns 2 and 4) were unfamiliar to at least one learner.

The first thing to notice about this data is that the figures for both groups are remarkably similar. Second, a surprising number of learnable words were used or negotiated for form but without any explicit negotiation of meaning. These are words that at least one learner in a group did not know in the pre-test. Conversely, only a small proportion of 
Table 7. Level of engagement with unknown words (percentages in parentheses).

\begin{tabular}{lccccc}
\hline & \multicolumn{3}{l}{ Group I } & & \multicolumn{2}{c}{ Group 2 } \\
\cline { 2 - 3 } \cline { 5 - 6 } & I. Words & $\begin{array}{c}\text { 2. Learnable } \\
\text { words' }\end{array}$ & & 3. Words & $\begin{array}{c}\text { 4. Learnable } \\
\text { words }\end{array}$ \\
\hline I. Not used & $30(28)$ & $22(28)$ & & $37(34)$ & $25(33)$ \\
2. Used & $45(4 I)$ & $25(32)$ & & $42(39)$ & $24(32)$ \\
3. Negotiation of form (NoF) & $21(19)$ & $19(24)$ & & $17(16)$ & $15(20)$ \\
4. Negotiation of meaning (NoM) & $13(12)$ & $13(16)$ & & $13(12)$ & $12(16)$ \\
Total & $109(100)$ & $79(100)$ & & $109(100)$ & $76(100)$ \\
\hline
\end{tabular}

Notes. 'Learnable words are words that at least one member of the group did not recognize in the pre-test. ${ }^{2} \mathrm{~A}$ further 13 words from the task input sheets which were inadvertently not included in the tests were negotiated for meaning.

unknown words were negotiated for meaning. We next look at the quality of the negotiation of meaning that occurred.

\section{How accurate was learner-learner negotiation of unfamiliar words?}

To address the question of how accurately the learners negotiated meaning, the information they supplied to each other in response to indications that a word was not known was analysed. As shown in Table 8, learners initiated 49 instances of negotiation of word meaning. In 29 cases (59\%), other learners responded with accurate information on word meaning. An 'accurate' response was defined as any response which provided relevant information about the meaning of the word regardless of the amount or level of specificity of this information (for examples, see Table 6 above). In 11 further cases, interlocutors responded with information on word form (for example, by spelling out a word or repeating it) but not meaning. Only two negotiations produced incorrect information. Both cases involved a polysemous word (alarm) for which accurate meanings were given but not the meanings needed for the task context. The supervisors assisted with five words.

Table 8. The quality of responses to requests for clarification of unfamiliar words (Groups I and 2 combined across all task performances).

\begin{tabular}{lc} 
Quality of response & Number (percent) \\
\hline I. Accurate information provided by interlocutors & $29(59)$ \\
2. Information provided on word form only (e.g. spelling) & $1 \mathrm{I}(22)$ \\
3. Accurate information provided with supervisor assistance & $4(8)$ \\
4. Accurate information provided solely by supervisor & $\mathrm{I}(22)$ \\
5. Word-meaning request overlooked or avoided & $2(4)$ \\
6. Incorrect information provided & $2(4)$ \\
7. Total & $49(100)$ \\
8. Total number of unfamiliar words & 155 \\
\hline
\end{tabular}


This is a reasonably positive result when one considers that the learners only had recourse to each other and when all else failed, to the supervisor, to manage their encounters with new words. In only five cases was the supervisor required to help. We next consider the question of whether task type had any effect on willingness to negotiate either the form or meaning of unfamiliar words.

\section{Did the type of task the learners performed affect their willingness to negotiate unfamiliar words?}

Table 9 displays the distribution across the tasks of negotiating questions concerned with perception of word form or with understanding of word meaning. Whereas Table 7 reported the number of words which were negotiated, this data focuses on the number of negotiating questions. The difference is of course that the same word may be the subject of multiple negotiating questions, and so here we can expect to see much larger cell sizes.

Table 9. The distribution of negotiating questions across the four tasks.

\begin{tabular}{|c|c|c|c|c|c|c|c|c|c|c|c|}
\hline \multirow{3}{*}{$\begin{array}{l}\text { Task type } \\
\text { Topic } \\
\text { Group }\end{array}$} & \multicolumn{4}{|c|}{ Opinion gap } & \multirow[t]{3}{*}{ Subtotal } & \multicolumn{4}{|c|}{ Information gap } & \multirow[t]{3}{*}{ Subtotal } & \multirow[t]{3}{*}{ I Total } \\
\hline & \multicolumn{2}{|c|}{ Surgery } & \multicolumn{2}{|c|}{ Zoo } & & \multicolumn{2}{|c|}{ Surgery } & \multicolumn{2}{|c|}{ Zoo } & & \\
\hline & 1 & 2 & 1 & 2 & & I & 2 & I & 2 & & \\
\hline Negotiation of meaning (NoM) & 17 & 5 & 32 & 28 & 82 & 10 & I & 7 & 5 & 23 & 105 \\
\hline Negotiation of form (NoF) & 32 & 7 & 28 & 26 & 93 & 134 & 101 & 109 & 113 & 457 & 550 \\
\hline Total & 49 & 12 & 60 & 54 & 175 & 144 & 102 & 116 & 118 & 480 & 655 \\
\hline
\end{tabular}

Three main points are worth noting in these results. First, the learners negotiated the form (negotiation of form, or NoF) of task vocabulary much more than meaning (negotiation of meaning, or NoM). In fact, more than five times as many negotiating questions were directed at clarifying the form of words (550) as were directed at meaning (105). Second, most of the negotiation questions were produced in the information gap tasks (480), with less than a third (175) produced in the opinion gap tasks. Third, and conversely, more than three quarters of negotiating questions seeking clarification of word meaning were produced in the opinion gap tasks (82 out of 105). Overall then, task type appeared to strongly influence the amount and type of attention paid to task vocabulary.

To summarize, many more unfamiliar words encountered in the tasks were used or negotiated for form than were negotiated for meaning. Of the relatively small number of words negotiated for meaning, the learners provided accurate information in about $60 \%$ of cases (29 out of 49) and only in two cases provided misleading information. Finally, when the distribution of negotiation across tasks was analysed, it revealed a strong pattern of form-focused negotiation in the information gap tasks, and a more even distribution of meaning-focused and form-focused negotiation in the opinion gap tasks.

We now turn to the question of what effect negotiation had on word learning. We first look at the overall results for learning that resulted from meeting unfamiliar words in the 
communication tasks before looking more closely at the role that negotiation played in this learning.

\section{Did the learners learn the meaning of unfamiliar words they met in communication tasks?}

Table 10 presents the results of the pre- and post-tests of task vocabulary (for a breakdown of results for each task, see Appendix 1). Learners recognized and provided meanings for substantially more words on the post-test. The largest gain in receptive recall for the four tasks was 21 words (S1) and the smallest, 12 words (S8). The average gain was 16 words. The pre-test and post-test results were subjected to a matched $t$-test, which gave an observed $t$-value of -4.67 and which allowed the null hypothesis to be rejected at the $p<0.001$ level of significance.

Table 10. Pre/post-test results for recognition of task vocabulary (109 words).

\begin{tabular}{llll}
\hline Student participants & Pre-test & Post-test & Post-test gains \\
\hline S1 & 51 & 71 & 20 \\
S2 & 71 & 92 & 21 \\
S3 & 77 & 88 & 11 \\
S4 & 69 & 85 & 16 \\
S5 & 68 & 79 & 11 \\
S6 & 60 & 78 & 18 \\
S7 & 60 & 75 & 15 \\
S8 & 66 & 78 & 12 \\
Mean & 65 & 91 & $16^{*}$ \\
\hline
\end{tabular}

Note. ${ }^{*} p<0.001$.

\section{Were negotiated words more likely to be learned than non- negotiated words?}

The relationship between levels of engagement with unfamiliar words and learning is reported on in Tables 11 and 12. Results are reported for the four levels of engagement with unfamiliar words described earlier (seen but not used, used without negotiation, negotiated for form, and negotiated for meaning). Two types of results are reported. The first three data columns show the number of unknown words at each level of engagement for which there were learning gains. These results do not report how many learners in each group did not know a word and showed post-test gains. This more nuanced data is provided in columns 4 and 5, with column 4 showing how many learners did not know the words in each category, and column 5 how many learning gains were made by all learners in a group for these words.

Learning, as measured in gains in post-test recall, occurred for more than half of the unfamiliar words encountered in the tasks ( $58 \%$ for both groups; see column 3 ). These gains were substantial for words from all four categories of engagement although, 
Table I I. Attention to task vocabulary and post-test gains: Group I (percentages in parentheses).

\begin{tabular}{|c|c|c|c|c|c|}
\hline \multirow[t]{2}{*}{ Category of use } & \multicolumn{3}{|l|}{ Words } & \multicolumn{2}{|l|}{ Learners } \\
\hline & $\begin{array}{l}\text { I. Words } \\
\text { tested }\end{array}$ & $\begin{array}{l}\text { 2. Unknown } \\
\text { words }\end{array}$ & $\begin{array}{l}\text { 3. Post-test } \\
\text { gains }\end{array}$ & $\begin{array}{l}\text { 4. Unknown words } \times \\
\text { four learners }\end{array}$ & $\begin{array}{l}\text { 5. Post-test gains } \\
\times \text { four learners }\end{array}$ \\
\hline a. Not used & 30 & 22 & $8(36)$ & 56 & $13(23)$ \\
\hline b. Used & 45 & 25 & $16(64)$ & 47 & $25(53)$ \\
\hline $\begin{array}{l}\text { c. Negotiation } \\
\text { of form }\end{array}$ & 21 & 19 & $12(63)$ & 41 & I7 (4I) \\
\hline $\begin{array}{l}\text { d. Negotiation } \\
\text { of meaning }\end{array}$ & 13 & 13 & $10(77)$ & 31 & $18(58)$ \\
\hline Total & 109 & 79 & $46(58)$ & 175 & 73 (42) \\
\hline
\end{tabular}

Table 12. Attention to task vocabulary and post-test gains: Group 2 (percentages in parentheses).

\begin{tabular}{|c|c|c|c|c|c|}
\hline \multirow[t]{2}{*}{ Category of use } & \multicolumn{3}{|l|}{ Words } & \multicolumn{2}{|c|}{ Learners (aggregated gains) } \\
\hline & $\begin{array}{l}\text { I. Words } \\
\text { tested }\end{array}$ & $\begin{array}{l}\text { 2. Unknown } \\
\text { words }\end{array}$ & $\begin{array}{l}\text { 3. Post-test } \\
\text { gains }\end{array}$ & $\begin{array}{l}\text { 4. Unknown words } \\
\times \text { four learners }\end{array}$ & $\begin{array}{l}\text { 5. Post-test gains } \\
\times \text { four learners }\end{array}$ \\
\hline a. Not used & 37 & 25 & $12(48)$ & 65 & 14 (22) \\
\hline b. Used & 42 & 24 & $16(67)$ & 52 & $24(46)$ \\
\hline $\begin{array}{l}\text { c. Negotiation } \\
\text { of form }\end{array}$ & 17 & 15 & $8(53)$ & 36 & $13(36)$ \\
\hline $\begin{array}{l}\text { d. Negotiation } \\
\text { of meaning }\end{array}$ & 13 & 12 & $8(67)$ & 36 & II (3I) \\
\hline Total & 109 & 76 & $44(58)$ & 189 & $62(33)$ \\
\hline
\end{tabular}

predictably, words that were not used in interaction showed the smallest gains (row a). The prediction that negotiated words would be more likely to be learnt was partially supported. As shown in columns 1 to 3 , for group 1,77\% of words negotiated for meaning were learnt compared to only $55 \%$ of words not negotiated for meaning (rows a, b and c). The figures for group $2(67 \%$ vs. 56\%) are similar. This prediction is also supported by the aggregated results across learners (column 5) for group 1 (58\% vs. $38 \%)$ but not for group 2 (31\% vs. 33\%).

On average, across groups 1 and 2 three out of every four words negotiated for meaning showed post-test gains ( 18 out of 25 or $72 \%$; see row c in columns 2 and 3 ) compared to an average of about two out of out of every four words that were not negotiated for meaning (72 out of 129 or $56 \%$; see rows a, b and c in columns 2 and 3). In terms of actual gains, however, a total of 72 words not negotiated for meaning showed post-test gains compared to 18 of the words negotiated for meaning. So while negotiation led to a better chance of learning, in fact, overall, many more words were learnt that were not negotiated.

What is surprising in these results is the improved recall of many words that had not been negotiated and indeed for words that were not used in interaction or were only negotiated for form. There are several possible explanations for this, including the 
possibility that the words may have already been partly known but with knowledge of form not secure enough for them to be recognized in the pre-test. Also, seeing an unfamiliar word and/or negotiating its form may have drawn attention to meaning which was then deduced from context clues either in the discussion or in the written input.

\section{Discussion}

The discussion focuses on two main themes: the relationship between type of task and negotiating behaviour, and the opportunities for vocabulary learning from communication tasks that lie both within and beyond negotiation of meaning.

Perhaps the most striking task type effect is that the information gap tasks produced more than twice as much negotiation of task vocabulary as the opinion gap tasks. However, much of this was directed at clarifying perception of the form of words. In the opinion gap tasks, on the other hand, much less negotiation occurred but more of this attended to word meaning. These patterns can be traced to the objectives and structure of the tasks and reflect the principle that 'attention is clearly related to purpose, which in turn is governed in large part by task demands' (Huckin and Coady, 1999, p. 183). Exchanging information orally without recourse to shared written material will necessarily require greater attention to accurate perception but less to meaning when the goal of the task is to recombine divided information to complete a task text (e.g. a picture or diagram). Thus, in the information exchange tasks the learners made few attempts to negotiate the meaning of unfamiliar words that they were recording on their task sheets. We see this in interaction 1 below, in which two of the interlocutors had not identified the word reptiles in the pre-test and yet despite actively negotiating the form of the word, at no time did they reveal this lack of knowledge or seek clarification of the meaning of the word. They subsequently failed to recognize it in the post-test. Indeed negotiation of form was 20 times more frequent in the information gap tasks than negotiation of meaning (see Table 9 above).

\section{Interaction 1:}

S5 yeah is a reptiles

S6 dicta what is this?

S5 r. e.p.

S6 r. e. p.

S5 t. i. 1 .

S6 t. i. 1 .

S8 reptile

S7 ah hang on, r. e. p.t. i. 1.

S5 1? e. s. yep reptiles and uh opposite this reptiles ...

S6 1. e. s. yep reptiles yes

S7 yes reptiles

S8 reptiles

S7 reptiles

On the few occasions when an interlocutor attempted to negotiate understanding of an unfamiliar word in these tasks it was typically passed over or ignored. In interaction 2, 
learner S7 spells out shed so that the learners can label a part of their diagram. Note that the lengthy negotiation sequence (which is already underway where the example begins) ends with an interlocutor saying, 'Yeah, ok, I don't worry, we just write down'; this is an explicit acknowledgment by the learner that the task goal could be met with minimum attention to the meaning of unfamiliar items.

Interaction 2:

S8 I don't know /sed/?

S7 s. h. e. d.

S5 / led/

S8 s. what's the meaning of /sed/?

S5 / /ed/ means some materials

S8 yeah? oh

S7 it's a whole name it's a feed - and a tool?

S8 - and tool /sed//sed/

S7 / $/ \mathrm{ed} /$

S8 yeah

S6 what's a spell? s. m.? s. h. e. d.

S8 s. h. e. d.

S7 s. h. e. d. and the tool is ah t. o. 1.?

S6 / /ed/ahhh

S5 / $\mathrm{ed} /$

S8 yeah

S6 ahh mmm yeah and?

S7 yeah ok I don't worry we just write down

In contrast, the problem-solving goal of the opinion gap tasks required greater depth of attention to the meaning of the word as in the following example:

Interaction 3:

S7 do you know what is number nine? yeah

S5 this one? dolphins, you know dolphin? ... dolphins yeah

S7 what animal's that?

S5 yeah sometimes they show it in the performance

S8 like swimming pool

S5 yes' swimming pool they jump up and they catch the-

S8 'yes

S5 -ball

S7 just something fish?

S5 like a shark but they are not dangerous

S8 oh yeah it's funny

S6 dangerous

Here, the learners needed to know the characteristics of each animal in order to solve a problem presented by the task. Even in this simple example, the need to negotiate meaning produces elaborative exploration of the word in question. Once understood, the word is retrieved during the task and used generatively, that is, used in new contexts (Joe, 1998), requiring the learners to make rich associations with existing 
knowledge (Baddeley, 1997). But while the opinion gap tasks prompted attention to word meaning, engagement in the task was optional (Doughty \& Pica, 1986) and learners could be more selective in the information they discussed. They may, for example, choose to avoid or ignore unfamiliar words that play a minor role in the task. In the phrase, 'divorced with custody of one son' from one of the opinion gap tasks, the word custody is somewhat redundant: 'a divorced person with a son' is a sufficient reading of the phrase. It is not surprising that none of the learners sought the meaning of this word or used it and that none could identify the word in the pretest or the post-test. In other words, learners gave priority to what they knew or what the task required them to know and did not spend time on words that could be avoided. 'Need' can be learner based or text based. Clearly, where in the input a word appears, and the role it plays, are important factors in determining how much attention learners will pay to it.

Negotiation also intrudes on the flow of interaction and entails some threat to face for the learner who has to admit that help is needed (Aston, 1986). So even in the opinion gap task there are good reasons to overlook some words and to perhaps feign comprehension of other words in the hope of inferring meaning from ongoing talk and context.

I now turn to the second theme of this discussion: the opportunities for vocabulary learning from communication tasks that lie both within and beyond negotiation of meaning. Effective retention of information requires attention (Schmidt, 1990) and is facilitated by depth of processing (Craik \& Tulving, 1975). Similarly, recall of new words is enhanced by meaningful, repeated and elaborated encounters (Baddeley, 1997; Joe, 1998). While I expected negotiation to provide the most favourable processing conditions, the results show that the learners used other strategic options to attend to vocabulary. Following Fraser (1999), I have classified these options under three headings: ignore, consult (negotiate), and infer.

\section{Ignore}

Ignoring the meaning of unfamiliar words was a common response by the learners in the study. This was particularly seen in the information gap tasks and in the comment in example 4 above, 'yeah ok I don't worry we just write down.' If learners are to meet task objectives efficiently then overlooking some difficulties is necessary to avoid being side-tracked by constant negotiation-side sequences (Foster, 1998). The time and attention available to focus on language form (i.e. on a new word) is limited when face-toface communication and the task objectives demand attention. Meeting words in the context of communication tasks creates the tension characteristic of the competing goals of learning and using language in communication; on the one hand a task stimulates generative and elaborative use of task content and vocabulary; on the other it inherently constrains attention to language learning goals. But not attending to words through explicit negotiation does not mean the learners are not attending to them in other ways. The substantial post-test gains for words that were not negotiated are an indication that the learners were making sense of task vocabulary from context without vocalizing the inferencing processes. 


\section{Negotiate (consult)}

When assistance was requested, the learners were generally good at providing it. Sometimes interlocutors responded by elaborating meaning over a series of turns (see interaction 3 above). In these cases the process of negotiating drew on a range of words from beyond the task. But usually the responses were brief and succinct, as seen in the sample of such responses in Table 6. In contrast to the brevity of these responses, Ellis (1995) found that responses by native speaker teachers to requests for clarification involved wordy and detailed explanations that appeared to impede learning. Ironically, the limited proficiency of the learners in the current study constrains the sophistication of their responses, possibly making these responses more easily comprehensible and usable than those obtained from native speakers in the Ellis study.

But was it necessary to be actively involved in negotiation to learn from it? The learners actively involved in seeking clarification only achieved eight of the 29 gains for negotiated words. The remaining 21 gains were all made by other members of the group. And so the act of seeking clarification did not appear to be of primary importance in determining who benefited from it. Two earlier studies (Ellis et al., 1994; Pica, 1992) also failed to find a significant advantage for active involvement over observing others negotiating. However, in a study looking at the development of question formation in ESL by adult learners, Mackey (1999) found a significant positive effect for active participation in negotiation compared to observing negotiation by others.

A final point concerns the source of the words that were negotiated. Unfamiliar vocabulary occurs in the written input for a task, in the verbal instructions, and in interlocutors' speech. The latter can provide a rich source of input as seen in the learners' use of the words performance, swimming pool, jump, catch, ball, fish, shark, funny, dangerous to explain the word dolphin in interaction 5. However, although the learners were frequently clarifying (negotiating) their mishearing of the mispronunciation of words spoken by other learners, all the words that they negotiated for meaning came from the written input of the tasks or use of this input by interlocutors. Upon reflection, this is not surprising. Unfamiliar words in interlocutors' speech are likely to be better known, more easily overlooked, more difficult to pinpoint, and perceived as less vital than words occurring in print. This gives a clear signal for task design: if learners are more likely to attend to words from the written input, then selecting or designing the worksheets should be done with an eye on the useful vocabulary they contain.

\section{Infer}

Post-test gains were recorded for over half of the unfamiliar words that were used but not negotiated. These gains occurred through meeting unfamiliar words in context and through productive use by interlocutors. Ostensibly, the gains show learners acquiring new semantic/conceptual information about words they meet in tasks. Meeting a word in a task in which it is embedded in networks of meaning may also trigger retrieval of existing but partially known information that may not have been activated when the word was met in a decontextualized list in the pre-test. This would account for the gains for words that were met in the task texts but not used in interaction. Such words may have been poorly known as distinct from unfamiliar. 


\section{Conclusions}

The present study showed adult ESL learners picking up the meaning of unfamiliar words encountered incidentally in task materials as they worked collaboratively on communication tasks. In almost all cases, this learning occurred without access to external sources of information on the meaning of the words. Averaged across learners and tasks, the post-test gains approximate to four instances of word learning per 30 minutes of task work, a gain measured three days after the words were met in the tasks. Seen as a proportion of unfamiliar words in the pre-test these are gains of around one in every three unfamiliar words met in the tasks. This compares favourably to rates of vocabulary learning recorded in other studies. Nagy et al. (1985), in research on L1 vocabulary learning through reading, report on a one in 10 to one in 20 chance of an unfamiliar item being learned. In a second language (L2) context, Horst, Cobb and Meara (1998) report learning of about one in five words encountered in a graded reader. The vocabulary enrichment reported in the present study is a particularly favourable result when we consider that it occurs as a secondary benefit alongside the goals more typical of group work: fluency development, discourse competence and understanding curriculum content. As promising as these results are, the small sample size in the study requires a degree of caution in interpreting and generalizing from the results. Clearly, larger replications in different instructional contexts and with different tasks and task types are warranted.

To conclude, two further findings from the study are worth highlighting. First, the type of task learners work on affects the kind of attention they pay to unfamiliar task vocabulary. The processes and outcomes required by the different task types in the study influenced the degree to which the learners focused their negotiation on the meaning or the form of task vocabulary. When the task required the learners to accurately record information given them by interlocutors in the information exchange tasks, they attended to accuracy of perception but showed little concern with meaning. When, on the other hand, the task required them to use the task content to solve problems, they attended to the meaning but had little need to attend to form because the task materials were seen by all. The results are a clear signal that the nature of a task plays an important and predictable role in directing learners' attention to vocabulary in productive ways. There is therefore much to be gained from careful choice of vocabulary and sensitivity to the task operations that will best encourage generative and elaborative use of those words.

Second, and finally, negotiation does not account for most learning. The learning of unfamiliar words occurred in three ways in the study, all of them of significance in communication tasks: learning through meeting unfamiliar words in context; learning through negotiation; and learning through observing negotiation. While words that were negotiated for meaning showed a better chance of retention than other words, many more words were learnt that had not been negotiated. This finding echoes similar conclusions reached by Foster and Ohta (2005), that giving too much weight to negotiation of meaning restricts attention to dialogic exchanges attending to communication problems when in fact non-problematic cooperative interaction also plays an important role in enhancing understanding of and control over new vocabulary met in communication tasks. 


\section{Funding}

This research received no specific grant from any funding agency in the public, commercial or not-for-profit sectors.

\section{References}

Adams, R. (2007). Do second language learners benefit from interacting with each other? In A. Mackey (Ed.), Conversational interaction in second language acquisition: A series of empirical studies (pp. 29-52). Oxford: Oxford University Press.

Aston, G. (1986). Trouble-shooting in interaction with learners: The more the merrier? Applied Linguistics, 7, 128-143.

Baddeley, A. (1997). Human memory: Theory and practice. Revised edition. Hove: Psychology Press.

Craik, F.I.M., \& Tulving, E. (1975). Depth of processing and the retention of words in episodic memory. Journal of Experimental Psychology, 104, 268-294.

De La Fuente, M.J. (2002). Negotiation and oral acquisition of L2 vocabulary: The roles of input and output in the receptive and productive acquisition of words. Studies in Second Language Acquisition, 24, 81-112.

Doughty, C. (2000). Negotiating the L2 linguistic environment. University of Hawaii Working Papers in ESL, 18, 47-83.

Doughty, C., \& Pica, T. (1986). Information gap tasks: Do they facilitate SLA? TESOL Quarterly, $20,305-325$.

Eckerth, J. (2009). Negotiated interaction in the L2 classroom. Language Teaching, 42, 109-130.

Ellis, R. (1991). The interaction hypothesis: A critical evaluation. In E. Sadtono (Ed.), Language acquisition and the second/foreign language classroom (pp. 179-211). Singapore: RELC Anthology Series 28.

Ellis, R. (1995). Modified oral input and the acquisition of word meanings. Applied Linguistics, 16, 409-441.

Ellis, R., \& He, X. (1999). The roles of modified input and output in the incidental acquisition of word meanings. Studies in Second Language Acquisition, 21, 319-333.

Ellis, R., Tanaka, Y., \& Yamazaki, A. (1994). Classroom interaction, comprehension, and the acquisition of L2 word meanings. Language Learning, 44, 449-491.

Foster, P. (1998). A classroom perspective on the negotiation of meaning. Applied Linguistics, 19, 1-23.

Foster, P., \& Ohta, A.S. (2005). Negotiation for meaning and peer assistance in second language classrooms. Applied Linguistics, 26, 402-430.

Fraser, C. (1999). Lexical processing, strategy use and vocabulary learning through reading. Studies in Second Language Acquisition, 21, 225-241.

Gass, S. (1997). Input, interaction and the second language learner. Mahwah, NJ: Lawrence Erlbaum.

Gass, S., Mackey, A., \& Pica, T. (1998). The role of input and interaction in second language acquisition: Introduction to the special issue. Modern Language Journal, 82, 299-307.

Gass, S., Mackey, A., \& Ross Feldman, L. (2005). Task-based interactions in classroom and laboratory settings. Language Learning, 55, 575-611.

Hall, S. (1991). The effects of split information tasks on the acquisition of mathematics vocabulary. Unpublished MA dissertation, Victoria University of Wellington, Wellington, New Zealand.

Horst, M., Cobb, T., \& Meara, P. (1998). Beyond a clockwork orange: Acquiring second language vocabulary through reading. Reading in a Foreign Language, 11, 207-233.

Huckin, T., \& Coady, J. (1999). Incidental vocabulary acquisition in a second language: A review. Studies in Second Language Acquisition, 21, 181-193. 
Hulstijn, J.H. (2001). Intentional and incidental second-language vocabulary learning: A reappraisal of elaboration, rehearsal and automaticity. In P. Robinson (Ed.), Cognition and second language instruction (pp. 258-286). Cambridge: Cambridge University Press.

Joe, A. (1998). What effect do text-based tasks promoting generation have on incidental vocabulary learning. Applied Linguistics, 19, 357-377.

Kim, Y.J. (2008). The role of task-induced involvement and learner proficiency in L2 vocabulary acquisition. Language Learning, 58, 285-325.

Laufer, B., \& Hulstijn, J. (2001). Incidental vocabulary acquisition in a second language: The construct of task-induced involvement. Applied Linguistics, 22, 1-26.

Long, M.H. (1980). Input, interaction and second language acquisition. Unpublished doctoral dissertation, University of California, Los Angeles, CA, USA.

Long, M.H. (1996). The role of the linguistics environment in second language acquisition. In W.C. Ritchie \& T.K. Bhatia (Eds.), Handbook of language acquisition: Volume 2: Second language acquisition (pp. 413-468). New York: Academic Press.

Long, M.H., \& Robinson, P. (1998). Focus on form: Theory, research and practice. In C.J. Doughty \& J. Williams (Eds.) Focus on form in second language acquisition (pp. 15-41). Cambridge: Cambridge University Press.

Lyster, R. (1998). Negotiation of form, recasts, and explicit correction in relation to error types and learner repair in immersion classrooms. Language Learning, 48, 183-218.

Lyster, R., \& Ranta, L. (1997). Corrective feedback and learner uptake. Studies in Second Language Acquisition, 19, 37-66.

Mackey, A. (1999). Input, interaction, and second language development. Studies in Second Language Acquisition, 21, 557-587.

Mackey, A. (Ed.). (2007). Conversational interaction in second language acquisition: A collection of empirical studies. Oxford: Oxford University Press.

Nagy, W.E., Herman, P.A., \& Anderson, R.C. (1985). Learning words from context. Reading Research Quarterly, 20, 233-253.

Nakahama, Y., Tyler, A., \& Van Lier, L. (2001). Negotiation of meaning in conversation and information gap activities: a comparative discourse analysis. TESOL Quarterly, 35, 377-405.

Nation, I.S.P. (2001). Learning vocabulary in another language. Cambridge: Cambridge University Press.

Nation, I.S.P., \& Heatley, A. (1996). VocabProfile, Word, and Range: Programs for processing text. Victoria: LALS, Victoria University of Wellington.

Pica, T. (1992). The textual outcomes of native speaker-non-native speaker negotiation: What do they reveal about second language learning? In C. Kramsch \& S. McConnell-Ginet (Eds.), Text and context: Cross-disciplinary perspectives on language study (pp. 198-237). Lexington, MA: Heath.

Pica, T. (1994). Research on negotiation: What does it reveal about second language learning conditions, processes and outcomes? Language Learning, 44, 493-527.

Pica, T., Kanagy, R., \& Falodun, J. (1993). Choosing and using communication tasks for second language instruction. In G. Crooks \& S. Gass (Eds.), Tasks and language learning: Integrating theory and practice (pp. 9-34). Clevedon: Multilingual Matters.

Pica, T., Lincoln-Porter, F., Paninos, D., \& Linnell, J. (1996). Language learners' interaction: How does it address the input, output, and feedback needs of L2 learners? TESOL Quarterly, 30, 59-84.

Saragi, T., Nation, I.S.P., \& Meister, G.F. (1978). Vocabulary learning and reading. System, 6, 72-78.

Schmidt, R. (1990). The role of consciousness in second language learning. Applied Linguistics, $11,129-158$.

Slimani-Rolls, A. (2005). Practitioner research: Rethinking task-based language learning: What we can learn from the learners Language Teaching Research, 9, 195-218. 
Smith, B. (2003). Computer-mediated communication: An expanded model. The Modern Language Journal, 87, 38-57.

Smith, B. (2005). The relationship between negotiated interaction, learner uptake, and lexical acquisition in task-based computer-mediated communication. TESOL Quarterly, 39, 33-58.

Swain, M. (1995). Three functions of output in second language learning. In G. Cook \& B. Seidlhofer (Eds.), Principles and practice in applied linguistics (pp. 125-144). Oxford: Oxford University Press.

Ur, P. (1981). Discussions that work. Cambridge: Cambridge University Press.

Van den Branden, K. (1997). Effects of negotiation on language learners' output. Language Learning, 47, 589-636.

Appendix I. Pre/post-test results for recognition of task vocabulary (I09 words) by task and task type.

\begin{tabular}{|c|c|c|c|c|c|c|c|c|c|}
\hline \multirow{2}{*}{$\frac{\text { Task type }}{\text { Topic }}$} & \multicolumn{2}{|c|}{ Opinion gap } & \multirow[t]{2}{*}{ Subtotal } & \multicolumn{2}{|c|}{ Information gap } & \multirow[t]{2}{*}{ Subtotal } & \multirow[t]{2}{*}{ Subtotal } & \multirow[t]{2}{*}{ Losses } & \multirow[t]{2}{*}{ Total } \\
\hline & Surgery & $\overline{Z o o}$ & & Surgery & Zoo & & & & \\
\hline $\mathrm{SI}$ & 7 & 5 & 12 & 4 & 5 & 9 & 21 & I & 20 \\
\hline $\mathrm{S} 2$ & 4 & 4 & 8 & 5 & 9 & 14 & 22 & I & 21 \\
\hline S3 & I & 2 & 3 & 7 & 3 & 10 & 13 & 2 & 11 \\
\hline S4 & I & 6 & 7 & 7 & 3 & 10 & 17 & I & 16 \\
\hline $\begin{array}{l}\text { Task type total: } \\
\text { Group I }\end{array}$ & 13 & 17 & 30 & 23 & 20 & 43 & 73 & 5 & 68 \\
\hline S5 & 4 & 3 & 7 & 3 & 2 & 5 & 12 & I & 11 \\
\hline S6 & 6 & 3 & 9 & 7 & 4 & 11 & 20 & 2 & 18 \\
\hline S7 & 4 & 5 & 9 & 3 & 6 & 9 & 18 & 3 & 15 \\
\hline S8 & 3 & 3 & 6 & 5 & I & 6 & 12 & 0 & 12 \\
\hline $\begin{array}{l}\text { Task type total: } \\
\text { Group } 2\end{array}$ & 17 & 14 & 31 & 18 & 13 & 31 & 62 & 6 & 56 \\
\hline Total & 30 & 31 & 61 & 41 & 33 & 74 & 135 & II & 124 \\
\hline
\end{tabular}

